\title{
MOVIMENTO DA MATEMÁTICA MODERNA - POSSÍVEIS LEITURAS DE UMA CRONOLOGIA
}

\section{Modern Mathematics Movement - Possible Interpretations of a Chronology}

\author{
Maria Célia Leme da Silva ${ }^{1}$
}

\section{Resumo}

O artigo apresenta uma cronologia de 1950 a 1976, construída a partir de um inventário sobre teses e dissertações sobre o Movimento da Matemática Moderna no Brasil realizada pelo GHEMAT. Discute em seguida possíveis interpretações sobre a cronologia apresentada utilizando a discussão monumento/documento proposta pelo historiador Jacques Le Goff (1992).

Palavras-chave: Movimento da Matemática Moderna; Cronologia, Monumento/documento.

\section{Abstract}

The paper presents a chronology of 1959 to 1976, constructed on the basis on the GHEMAT inventory of theses and dissertations related to the Modem Mathematics Movement. The text considers possible interpretations of this chronology, utilizing the discussion monument/document proposed by the historian Jaques Le Goff (1992).

Keywords: Modern Mathematics Movement; Chronology, Monument/ document.

1 GHEMAT - PUC/SP - celials@pucsp.br 


\section{Introdução}

O presente artigo tem como objetivo apresentar uma cronologia de fatos importantes relacionados com o Movimento da Matemática Moderna no Brasil no período de 1950 a 1976, obtida a partir de um inventário realizado pelo GHEMAT - Grupo de Pesquisa História da Educação Matemática no Brasil - e tecer considerações sobre diferentes formas de interpretar esta cronologia.

O GHEMAT vem trabalhando na produção histórica da Educação Matemática e considera o percurso da produção histórica como sendo: um interesse de pesquisa, a formulação de questões históricas legítimas, um trabalho com os documentos e a construção de um discurso que seja aceito pela comunidade (VALENTE, 2005).

Para interpretar a cronologia apresentada nos apoiaremos no artigo Documento/Monumento (1992) do historiador Jacques Le Goff. Nele, o autor faz uma análise sobre as diferentes formas de produção da história ao longo dos tempos, discutindo a relação existente entre documento e monumento. Ao discutir a contemporaneidade, ele chama a atenção para o dever principal do historiador: a crítica do documento - qualquer que seja ele - enquanto monumento. $\mathrm{O}$ documento não é qualquer coisa que fica por conta do passado, é um produto da sociedade que o fabricou segundo as relações de força que aí detinham o poder (p. 545). Neste sentido, um documento ao chegar em nossas mãos, hoje, adquire importância e ganha status de monumento. Mais à frente, Le Goff reitera sua posição em relação ao documento:

O documento não é inócuo. É antes de mais nada o resultado de uma montagem, consciente ou inconsciente, da história, da época, da sociedade que o produziram, mas também das épocas sucessivas durante as quais continuou a ser manipulado, ainda que pelo silêncio. $\mathrm{O}$ documento é uma coisa que fica, que dura, e o testemunho, o ensinamento que ele traz devem ser em primeiro lugar analisados desmistificando-lhe o seu significado aparente. O documento é monumento (p. 547-548).

Finalmente, Le Goff salienta que o monumento vem revestido de uma roupagem, uma aparência enganadora, uma montagem e diz que cabe ao historiador desmontar, demolir esta roupagem e analisar as condições de produção dos documentos-monumentos.

\section{Sobre o Movimento da Matemática Moderna}

Nos anos 60, o ensino de Matemática no Brasil, e também em outros países, sofreu a influência do chamado Movimento da Matemática Moderna 
(MMM), que buscava aproximar a Matemática ensinada na escola básica com a Matemática produzida pelos pesquisadores da área. Como conseqüência, as propostas defendidas pelo Movimento enfatizam as estruturas algébricas, a teoria dos conjuntos, a topologia, as transformações geométricas, entre outras.

O Grupo de Pesquisa de História da Educação Matemática no Brasil - GHEMAT - está desenvolvendo um projeto de investigação com o objetivo de analisar historicamente o MMM no Brasil. A primeira etapa para o desenvolvimento deste projeto, realizada durante o segundo semestre de 2004 e o primeiro semestre de 2005, foi o estudo das teses e dissertações que tratavam do MMM no Brasil. O nosso objetivo era inventariar as pesquisas sobre o tema e identificar lacunas, questões, do ponto de vista da produção histórica, que não haviam sido discutidas até então, o que justificaria o desenvolvimento de novos projetos de investigação sobre o MMM no Brasil. Um dos frutos do inventário realizado foi a elaboração de uma cronologia, que discutiremos a seguir.

\section{Uma Cronologia por meio de teses e dissertações sobre o MMM}

A cronologia que será apresentada e analisada neste artigo compreende o período de 1950 até 1976 . O período escolhido para compor a cronologia tem por finalidade caracterizar o período anterior ao MMM, sua chegada ao Brasil, desenvolvimento e declínio. Outro dado importante a ser explicitado é que a grande maioria dos acontecimentos selecionados para integrar a cronologia é relatada e comentada na maioria das pesquisas inventariadas. A seguir, apresentamos a cronologia, com comentários extraídos das teses e dissertações sobre o MMM no Brasil:

1950 CIEAEM (Comission internationale pour l'étude et l'amélioration de l'en seignement des mathématiques).

Em 1950, iniciou-se uma série de encontros promovidos pelo CIEAEM. A comissão propunha-se a coordenar o trabalho que já era realizado, psicológico, metodológico e prático, no sentido da melhoria do ensino da matemática, por diferentes profissionais em diferentes países (BURIGO, p.71).

1951 UICSM (University of Illinois Committee on School Mathematics).

Com o fim da II Guerra Mundial, a sociedade americana começa a perceber que não é suficiente preparar alunos da escola secundánia para uma competência funcional, que tem sido definida pelo movimento de educação progressivo como a matemática do dia-a-dia na sociedade. É necessánio redefinir competência funcional em termos modernos, que são desenvolvidos 
rapidamente na sociedade tecnológica. Muitos setores da sociedade requerem pessoas com alto treinamento matemático (.. ). Assim, muitos comitês foram formados e conseqüentemente muitas recomendações foram feitas para a reforma da educação secundária, mas somente com a fundação da UICSM em 1951 que ações foram tomadas no sentido de colocar em prática as recomendações. O UICSM, financiado com verba federal, desenvolveu materiais de classe, testou em escolas e treinou professores para usá-los.(...) O diretor deste projeto foi Max Beberman (...).O projeto do UICSM foi caracterizado pela precisão de linguagem e aprendizagem pela descoberta (D’AMBROSIO, p.60-62).

1954 UMI (Union Mathématique Internationale) em assembléia Geral, decidiu pela reorganização de sua Comission Internationale de l'Enseignement Mathématique (CIEM), criada em 1908.

A principal atividade da CIEM era a organização de simpósios para a discussão de temas considerados significativos para o ensino de matemática. Contava, também com um órgão de publicação regular - a revista "L'Enseignement Mathématique" (BURIGO, p.72).

1955 Publicado $1^{\circ}$ livro do CIEAEM com textos do epistemólogo Jean Piaget, dos matemáticos Dieudonné, Choquet e Lichnerowicz, do lógico Beth e do pedagogo Caleb Gattegno.O livro teve repercussão internacional e foi divulgado no Brasil no II Congresso Nacional de Ensino de Matemática, em 1957 (BURIGO, p. 71-72).

\section{I CONGRESSO NACIONAL DE ENSINO DE MATEMÁTICA realizado em Salvador, Bahia.}

Teve a participação de 94 professores, contou com a presença de representantes do Distrito Federal (Rio de Janeiro), São Paulo, Rio Grande do Sul, Espírito Santo, Pernambuco, Rio Grande do Norte, além da Bahia. Podemos citar a presença de Manoel Jairo Bezerra, Osvaldo Sangiorgi, Omar Catunda e Ana Averbuch (SOARES, p. 67$68)$.

Neste congresso, não há evidências da introdução de tópicos da matemática moderna. Entretanto, muitas das discussões tratam do programa secundário e da necessidade de reorganizá-lo para uma aprendizagem mais eficiente neste nível (D 'AMBROSIO, p.85).

Nas conclusões, votadas em plenário, propunham-se programas "flexíveis e sujeitos a revisões periódicas" (...) O Congresso condenava 0 que era considerado um ensino "excessivamente abstrato, teórico", "livresco" e propunha um ensino que enfatizasse as aplicações, "a conexão entre a Matemática e as outras Ciências" e "a evolução histó- 
rica da Matemática". A necessidade de uma maior valorização do ensino da matemática no secundário expressava-se na resolução aprovada, que propunha o aumento da carga horária semanal para quatro aulas no ginásio e cinco no colégio e era justificada, de um lado, pelo caráter disciplinador do "espírito inerente à disciplina e, de outro, pela influência da matemática no progresso científico em gera" (BURIGO, p. 42-43).

1957 Lançamento do primeiro foguete soviético, o SPUTNIK.

\section{Criação do Colégio de Aplicação da USP}

O colégio foi criado por um convênio entre a Secretaria de educação e a Faculdade de Filosofia da USP. Além de servir à prática docente dos estudantes da Faculdade, um objetivo estabelecido para os Colégios de Aplicação por lei federal em 1946, o Colégio deveria existir como espaço de "ensaios de renovação pedagógica" e investigação educacional (BURIGO, p. 143). Em 1958, Scipione Di Pierro Neto presta concurso e é aprovado como Coordenador de Matemática do colégio.

\section{II CONGRESSO NACIONAL DE ENSINO DE MATEMÁTICA, realizado em Porto Alegre, Rio Grande do Sul.}

Participaram mais de 400 professores, entre eles Júlio César de Melo e Souza, Benedito Castrucci, Manoel Jairo Bezerra e Osvaldo Sangiorgi. O tema Matemática Moderna foi abordado, ainda que discretamente, nas teses de Ubiratan D’Ambrósio e de Osvaldo Sangiorgi, de São Paulo, e de Jorge Emmanuel Ferreira, representante do Colégio Militar do Rio de Janeiro e de Martha Maria de Sousa Dantas, da Bahia.(SOARES, p. 71-72).

Surge a primeira argumentação brasileira em favor da Matemática Moderna. (BURIGO, p. 47).

Nos anais deste congresso, há evidências de sugestões para introduzir tópicos da matemática moderna no ensino primário e secundário. Em particular, Odila Barros propõe um programa em serviço para professores primários de matemática, no qual inclui: teoria dos conjuntos, correspondência biunívoca, propriedades dos conjuntos, e diferentes sistemas de numeração. No secundário, D’Ambrósio sugere a introdução do estudo de propriedades de diferentes conjuntos numéricos e estruturas algébricas de operações, assim como as estruturas que podem ser observadas nas transformações geométricas. Sangiorgi, por outro lado, afirma: "Cremos que as teorias cada vez 
mais complexas, a que é conduzida a investigação moderna, revelam-se pouco susceptíveis de virem a ser já incorporadas no ensino secundário...essa modelação aos tempos novos deve ser gradativa a fim de serem evitados os malefícios decorrentes de transformações radicais...(D 'AMBROSIO, p. 87-88).

\section{SMSG - School Mathematics Study Group.}

O trabalho de maior repercussão foi do Schhool Mathematics Study Group (SMSG), iniciado em 1958. O grupo foi criado a partir de duas conferências, uma delas promovida pela National Science Foundation (NSF), em que a baixa qualidade de ensino elementar e secundário foi apontada como um dos fatores responsáveis pela escassez de matemáticos pesquisadores e teve a assistência do National Council of Teachers of Mathematics (...) O SMSG produziu textos para todos os graus do ensino elementar e secundário, onde vários tópicos novos eram introduzidos, textos para professores e várias monografias destinadas aos alunos mais bem 'dotados' do final do curso secundário (BURIGO, p. 70).

Os participantes do SMSG eram matemáticos, professores de matemática, educadores, psicólogos e representantes da comunidade científica e tecnológica. Inicialmente, seu maior objetivo foi escrever livros de matemática moderna para o ensino secundário. O material produzido foi traduzido para 15 línguas diferentes (D 'AMBROSIO, p. 65-66).

\section{III CONGRESSO BRASILEIRO DO ENSINO DA MATEMÁTICA, REALI- ZADO NO RIO DE JANEIRO.}

Contou com a participação de cerca de 500 professores de matemática, entre os quais podemos citar os professores Osvaldo Sangiorgi, José Carlos de Mello e Souza, Haroldo Lisboa da Cunha, Martha Maria de Sousa Dantas, Ary Quintela, Manoel Jairo Bezerra, Martha Blauth Menezes, Ana Averbuch, Waldecyr C. de Araújo Pereira, Ruy Madsen Barbosa, Elon Lages Lima, Omar Catunda e Leônidas H. B. Hegenberg, entre outros (SOARES, p.74).

A necessidade da "aceleração da aprendizagem científica" como questão ligada ao "problema da defesa nacional" era um dos argumentos a justificar, com mais veemência, o estudo da "matemática moderna" pelos professores brasileiros. Três importantes resoluções foram aprovadas refletindo a nova atitude frente à matemática moderna: uma, recomendando cursos de aperfeiçoamento para professores registrados do ensino médio, de "preparação à Matemática Moderna", a se- 
gunda, recomendando a introdução do "espírito" da MM nas Faculdades de Filosofia, e, finalmente, uma resolução que propunha a realização de experiências no secundário com introdução de "noções de MM, a serem relatadas no IV Congresso" (BURIGO, p. 48-49).

\section{Matemática Moderna: EUA convidam professores brasileiros para curso.}

Osvaldo Sangiongi havia participado de um seminário de verão na Universidade de Kansas, como muitos outros professores da América Latina, na mesma época: "Fui convidado a participar dessas reuniões, fiquei lá quatro messes, sabendo o que aquele pessoal estava realizando, verificando que o governo americano tinha uma preocupação que nós aqui quase nunca temos que é de reciclar os professores" (Sangiorgi - depoimento oral para BURIGO, p. 104).

Nessas classes, eram usados os livros didáticos elaborados por grupos de estudos americanos como SMSG, Mathematical Association of América, Commitee on School Mathematics - Illinois, entre outros, em fase de experimentação. (...) Durante sua temporada no Kansas, Sangiorgi teve também a oportunidade de entrar em contato com 0 matemático George Springer (SOARES, p. 80-81).

Em 1960, o primeiro curso em serviço para professores secundários organizado pela IBECC/OAS/NSF foi realizado em São Paulo. Foi no estilo dos Institutos de verão dos EUA e professores do EUA foram convidados para apresentar novas idéias surgidas dos EUA (D'AMBROSIO, p. 93-94).

1961 Sangiorgi volta dos EUA: curso para professores sobre Matemática Moderna.

De volta ao Brasil, Sangiorgi conseguiu organizar o curso de aperfeiçoamento por meio de um acordo com a National Science Foundation, que garantiu a vinda de Sprigner, com a Secretaria de Educação e o Instituto Mackenzie, onde o curso foi realizado (...)O curso tinha quatro disciplinas (...) Alguns alunos foram os primeiros professores a desenvolverem experiências em termos de Matemática moderna (...) (BURIGO, p. 105).

1961 Criação do GEEM (Grupo de Estudos do Ensino da Matemática) em 31 de outubro.

O grande impulso, entretanto, o marco decisivo para a constituição do movimento da Matemática moderna no Brasil, que permitiu a divulgação ampla da nova proposta para além de círculos restritos de 
educadores e a realização de experiências apoiadas numa discussão articulada foi, sem dúvida, a criação do GEEM, em São Paulo. (BURIGO, p. 104).

\section{IV CONGRESSO BRASILEIRO DE ENSINO DA MATEMÁTICA realiza- do em Belém, Pará.}

Pela primeira vez, o Congresso tinha como um de seus pontos de pauta a "Introdução da Matemática Moderna na Escola Secundária" (BURIGO, p. 108).

Embora os anais deste congresso nunca tenham sido publicados, alguns artigos apresentados no congresso foram incluídos nas publicações do GEEM de Matemática Moderna para o ensino secundário, publicado em 1962. Esses artigos eram na forma de palestras e incluíam seções menores discutindo a aplicabilidade da matemática escolar. Uma exceção foi o artigo feito pelo GEEM propondo um currículo mínimo para o desenvolvimento do novo programa de matemática para escola secundária $O$ programa proposto foi o primeiro a incorporar matemática moderna no currículo. (...) Para o secundário, a sugestão foi que os tópicos se aproximassem da teoria dos conjuntos e das estruturas algébricas. Maior ênfase foi dada ao estudo das propriedades das operações, o estudo de diferentes sistemas numéricos foi recomendado, assim como o estudo das funções (D 'AMBROSIO, p.89).

1962 Manifesto assinado por mais de 60 matemáticos canadenses e norteamericanos aponta equívocos pedagógicos da introdução de tópicos da MM (BURIGO, p. 89).

1962 Criação do NEDEM - Núcleo de Estudos e Difusão do Ensino da Matemática, no Paraná.

Foi coordenado pelo professor Osny Antônio Dacól. O grupo era constituído por professores, pedagogos, e psicólogos com atuação no magistério secundário de Curitiba e nas Faculdades de Filosofia, das Universidades Federal e Católica do Paraná e da Faculdade Estadual de Paranaguá. (...) O NEDEM encerrou suas atividades em meados da década de 70 (SOARES, p. 109110).

1963 Primeiro livro didático para a primeira série ginasial: "Matemática Moderna" de Osvaldo Sangiorgi (BURIGO, p. 109). 


\section{Início do trabalho com a MM no ensino elementar/primário.}

Foi somente em 1964 que o primeiro curso para professores primário foi oferecido. Os principais nomes associados com a reforma matemática primária foram Lucilia Bechara, Manhucia Libermann e Anna Franchi. Essas três mulheres, mais tarde, escreveram livro didático para o ensino de mat. no nível primário (D 'AMBROSIO, p.103).

1964 Convênio MEC-USAID é assinado

Durante os anos de 1964 a 1968 foi assinado. Essa ajuda permitiu prover com assistência técnica e financeira os órgãos educacionais brasileiros, instituições e autoridades.(...) No nível secundário, MECUSAID assumiu o financiamento da publicação das traduções dos materiais do SMSG assim como proveu fundos para os cursos em serviço necessários para ensinar os professores como usar esses materiais. ( ) Lafayette de Moraes e Lydia Lamparelli foram os responsáveis pela tradução do material do SMSG para o português (D 'AMBROSIO, p. 142, 138).

\section{V CONGRESSO BRASILEIRO DO ENSINO DA MATEMÁTICA realiza- do em São José dos Campos, São Paulo.}

O tema central do Congresso era a 'Matemática Moderna na Escola Secundária: articulações com o ensino primário e com o ensino secundário'. Contou com a participação de 450 educadores matemáticos de vários países. Dentre eles, destaca-se a participação de Marshall Stone (USA), Hector Merklen (Uruguai), George Papy (Bélgica/ Bruxelas, educador matemático cuja obra teve importante repercussão no Brasil mais tarde), Hellmut Volker (Argentina) (D’AMBROSIO, p.126 e BURIGO, p. 156).

Este congresso continuou com grande participação do GEEM, que se encarregou de sua organização. O temário deste V Congresso foi a Matemática Moderna na escola secundária, articulações com o ensino primánio e com o ensino universitário, e congregou cerca de 350 participantes. Este congresso trouxe pela primeira vez matemáticos estrangeiros a congressos brasileiros de ensino de Matemática (SOARES, p. 76).

\section{GEEM organiza a I OLIMPÍADA DE MATEMÁTICA}

GEEM realiza a primeira Olimpíada de Matemática do estado de São Paulo em 1967. Este evento foi organizado primeiramente pelo GEEM e pela Academia de Ciências do estado de São Paulo. O total de estudantes participantes foi aproximadamente de 100000 , do $1^{\circ}$ e $2^{\circ}$ ano do nível secundário inferior ( $5^{\circ}$ e $6^{\circ}$ série) (D AMBROSIO, p.129). 


\section{GEEM organiza a II OLIMPÍADA DE MATEMÁTICA}

A segunda olimpíada de matemática foi realizada em 1969, começando com encontros regionais em agosto. Desta vez, o $3^{\circ}$ e $04^{\circ}$ ano do secundário inferior ( $7^{\circ}$ e $8^{\circ}$ série) foram incluídos ( $D^{\prime A M B R O S I O,}$ p.129).

1970 Criação do GEEMPA - Grupo de Estudos sobre o Ensino da Matemática em Porto Alegre.

O grupo coordenado por Esther Pillar Grossi nasceu da preocupação de professores em melhorar o ensino de Matemática. (...) As atividades do GEEMPA foram muito influenciadas pelos trabalhos de George Papy e Zoltan Dienes. Em 1972, quando Dienes esteve em Porto Alegre, o GEEMPA realizou um curso de aperfeiçoamento para professores que reuniu perto de 2000 pessoas. (...) Hoje, o GEEMPA continua atuante, mas como uma proposta de trabalho multidisciplinar e sem estar ligado a nenhuma corrente em especial. O GEEMPA continua com a mesma sigla, mas mudou o seu nome para Grupo de Estudos sobre Educação, Metodologia de Pesquisa e Ação (SOARES, p. 108-109).

\section{Zoltan Paul Dienes}

O trabalho desenvolvido pelo GEEM teve uma influência importante de Dienes, com a divulgação de sua metodologia e dos 'blocos lógicos', por meio dos cursos para professores. O trabalho de Dienes foi certamente o esforço mais importante de desenvolvimento de uma proposta pedagógica consistente com as descobertas da psicologia piagetiana. (BURIGO, p.165, 171-174). Em 1971, Dienes esteve em São Paulo, a convite do GEEM, e durante uma semana participou de cursos para professores primários e secundários. É possível dizer que os trabalhos desenvolvidos por Dienes foram pelo menos de alguma forma e durante algum tempo vistos com uma alternativa contra os "exageros" cometidos em nome da MM. Nos jornais, os blocos lógicos e a metodologia de Dienes são vistos como um "novo caminho" ou anunciada como prenúncio de uma "renovação da Matemática", ou ainda como uma solução que vinha "amenizar a falta de apoio para o ensino da Matemática" chegando ao Brasil num momento de "maturidade em matéria de Matemática Moderna" (SOARES, p. 87). 


\section{$1971 \backslash 1$ “link0011”LDB (5691/ 71)}

A estrutura do sistema educacional foi alterada para $8+3$ anos de escolaridade. Os primeiros 8 anos correspondem ao $1^{\circ}$ grau e os outros 3 ao $2^{\circ}$ grau.

1973 Publicado nos Estados Unidos o livro de Morris Kline “O fracasso da Matemática Moderna” (STEPHAN, p. 108).

1973 Choquet fez a seguinte declaração:

Estou estarrecido com o que constato no ensino da escola primária e da secundária. Fui um dos promotores da reforma de ensino da Matemática, mas o que eu preconizava era simplesmente uma poda de galhos mortos, atravancadores, e a introdução de um pouco de álgebra. Pois bem, em suma, os novos programas e as instruções correspondentes são mais satisfatórios que os antigos, em que pesem erros razoáveis; mas há toda uma atmosfera nociva, que tem acompanhado seu desenvolvimento. Em particular, um ataque contra a geometria e contra os recursos da intuição: foi dito aos professores que seria lastimável que eles estudassem triângulos e que a álgebra linear substituiria toda a velha geometria... o resultado é tal que, sem uma forte reação de base, eu penso que a geração atual de nossa escola receberá uma formação matemática que não a prepara nem para a pesquisa, nem para a utilização da Matemática em técnicas ou ciências experimentais (SOARES, p. 112).

\section{$19739^{\circ}$ Colóquio Brasileiro de Matemática}

Começam os questionamentos sobre a eficácia do ensino de matemática moderna nas condições da educação brasileira (STEPHAN, p. 100). O professor Elon Lages de Lima (IMPA) afirmou que os excessos no uso da teoria dos conjuntos levaram a uma "conjuntivite" e "está sendo prejudicial pelo exagerado desligamento da realidade e por ser excessivamente moderno" (SOARES, p. 117-118).

\section{O próprio Sangiorgi reconheceu os erros que foram cometidos num artigo do jornal $O$ Estado de São Paulo.}

Nesse mesmo artigo, Sangiorgi apontou quais foram os principais efeitos da MM no ensino:

1. Abandono paulatino do salutar hábito de calcular (não sabendo mais tabuada em plena $5^{\circ}$ e $6^{\circ}$ séries!) porque as operações sobre conjuntos (principalmente com os vazios!) prevalecem acima de tudo; acrescenta-se ainda o exclusivo e prematuro uso das maquininhas de 
calcular, que se tornaram populares do mesmo modo que brinquedos eletrônicos.

2. Deixa-se ensinar frações ordinárias e sistema métrico decimal - de grande importância para toda a vida - para se aprender, na maioria das vezes incorretamente, a teoria dos conjuntos, que é extremamente abstrata para a idade que se encontra o aluno.

3. Não se sabe mais calcular áreas de figuras geométricas planas muito menos dos corpos sólidos que nos cercam, em troca da exibição de rico vocabulário de efeito exterior, como por exemplo "transformações geométricas".

4. Não se resolvem mais problemas elementares - da vida quotidiana - por causa da invasão de novos símbolos e de abstrações completamente fora da realidade, como: "O conjunto das partes de um conjunto vazio é um conjunto vazio?", proposto em livro de $5^{\circ}$ série. (SOARES, p. 116).

1976 É publicado, no Brasil, o livro de Morris Kline, “O fracasso da Matemática Moderna” (STEPHAN, p. 100-101).

1976 GEEM realiza o último curso de preparação de professores para o concurso de ingresso ao magistério. Segundo Lucilia Bechara, havia divergência entre os membros do GEEM acerca da validade da realização pelo Grupo de um curso daquela natureza (BURIGO, p. 200-201).

\section{Uma cronologia monumental}

Uma primeira leitura possível da cronologia apresentada sobre o MMM é como uma sucessão de monumentos. Ela permite a construção de uma visão global sobre o MMM no Brasil, destacando fatos importantes que influenciaram seu início, a forma como o Movimento foi apropriado e desenvolvido e finalmente as possíveis causas de seu fim. Consideramos que este olhar acerca da cronologia tem uma contribuição positiva na medida em que traça uma primeira caracterização sobre um fato histórico, o MMM, e pode ser utilizado como um passo inicial para a interpretação de como o MMM se deu no Brasil. No entanto, é preciso observar que tais acontecimentos, revestidos de monumentos, encontram-se rodeados de um poder, ganhando desta forma a roupagem e a aparência enganadora descrita por Le Goff.

Outro aspecto presente na interpretação da cronologia como monumentos é considerar datas e acontecimentos elencados numa ordem cronológica como acontecimentos lineares, um como conseqüência do outro. Por 
exemplo, uma interpretação possível para os seis Congressos Nacionais de Ensino da Matemática selecionados na cronologia é de que cada um deles é continuação do anterior, com os mesmos objetivos, importância e repercussão. Entretanto, tal interpretação é, no mínimo, questionável. Além disso, podese ter a sensação de que todos os componentes desta lista assumem o mesmo grau de relevância para a compreensão e interpretação do tema em questão, no caso , o MMM. Cada um dos acontecimentos selecionados para compor esta cronologia ganha destaque e torna-se referência, tornando-se monumentos representativos sobre o MMM.

Consideramos que a leitura da cronologia, como sucessão de monumentos, pode ser utilizada para produzir uma história. Ao assumir tal perspectiva, a história passa a ser considerada como linear, sem inseri-la num contexto maior, sem busca de explicações que justifiquem e dê significado a tais acontecimentos. Enfim, uma produção história sem crítica. Este é, do nosso ponto de vista, o uso não pertinente de uma cronologia.

\section{Uma cronologia documental}

Uma segunda leitura possível da cronologia é inicialmente tomar os acontecimentos e datas elencados como monumentos, mas não se contentar com eles. Ao assumirmos o papel de historiadores, compactuando com Le Goff, faz-se necessário desmontar, demolir esta construção e analisar as condições de produção dos documentos-monumentos. Em outras palavras, é preciso ir além dos monumentos, olhá-los por trás, avançar na busca de relações, intenções, condições, transformando monumentos em documentos a serem utilizados como fontes de pesquisa, que por sua vez, serão investigados, questionados criticamente e confrontados com outras fontes.

Selecionamos alguns acontecimentos da cronologia apresentada para fazermos uma primeira análise numa perspectiva crítica, levantando questionamentos que julgamos necessários serem investigados para que possamos ter uma compreensão melhor de como se deu o MMM no ensino de Matemática brasileiro.

Iniciamos a cronologia pontuando a criação e desenvolvimento de comitês e comissões tanto americanos como europeus com o intuito de melhorar o ensino da Matemática na educação básica, que certamente influenciaram, mais a frente, a maneira e a forma como o Brasil incorpora as idéias propagadas pelo MMM. Entretanto, não sabemos como tais comissões influenciaram a incorporação do MMM no Brasil, será que fomos mais influenciados pelas idéias norte-americanas? Ou será que pelas eu- 
ropéias? Em que medida, o MMM no Brasil se caracteriza como reprodução de modelos externos incorporados à Educação Matemática brasileira?

Outros acontecimentos que também merecem uma análise mais aprofundada dizem respeito aos seis Congressos Nacionais de Ensino de Matemática realizados no Brasil entre 1955 a 1966. As pesquisas apontam que o primeiro deles a iniciar uma discussão sobre o MMM é o II Congresso, realizado em 1957, mas somente em 1959, no III Congresso é que é claramente proposta a realização de experiências, contendo as propostas difundidas pelo MMM no secundário. Pois bem, se nos dois primeiros congressos não se tem a discussão do MMM, quais os temas tratados neles, quais as preocupações da comunidade de matemáticos e educadores matemáticos frente ao ensino da época? Haveria algum ensejo em torno das idéias propostas pelo MMM?

Uma segunda observação, ainda em relação aos congressos, é a presença do professor Osvaldo Sangiorgi, considerado como uma das grandes lideranças do MMM no Brasil, nesses três primeiros congressos, sem, contudo, propor a introdução das idéias do MMM, antes de 1957. A criação do GEEM como marco decisivo para a incorporação do MMM no Brasil acontece em 1961, logo após a volta do professor Sangiorgi da experiência vivenciada nos EUA. Uma possível leitura desses fatos é que a participação de Sangiorgi nos seminários nos EUA foi determinante na criação e implementação do GEEM e conseqüentemente na divulgação do MMM no Brasil. Aqui, cabe-nos levantar algumas questões, que ao nosso ver, ainda permanecem em aberto, como: Qual o motivo da implementação das propostas defendidas pelo MMM no ensino de Matemática brasileiro? Será devido a uma insatisfação de professores da época? Será uma forte influência das idéias desenvolvidas nos EUA e trazidas para o Brasil por Osvaldo Sangiorgi? E os demais matemáticos e educadores matemáticos, como se posicionaram frente a tais mudanças significativas no ensino de Matemática brasileiro?

Caminhando na cronologia, notamos que a partir de 1962 evidenciam-se manifestações contrárias ao MMM, num primeiro momento, por matemáticos canadenses e norte-americanos. Em 1973, é publicado o livro de Morris Kline que traz a público as divergências e problemas causados pelo MMM. No Brasil, o livro é publicado em 1976, período em que o MMM ainda encontra-se muito fortemente presente no ensino de Matemática brasileiro, mesmo com o próprio Osvaldo Sangiorgi reconhecendo certos erros em 1975. Novamente, levantamos mais questões: Qual foi o impacto desta obra no Brasil? Chegou a ser determinante para a contínua diminuição das idéias do MMM no ensino de Matemática brasileiro? Enfim, quais as razões pelas quais o MMM vai perdendo sua força? 


\section{Considerações Finais}

Acreditamos que as questões levantadas a partir da transformação da cronologia monumental em cronologia documental ainda encontram-se em aberto e requerem novas investigações, no sentido de ampliar a compreensão dos acontecimentos que compõem a cronologia e confrontá-los com outras fontes de pesquisa de modo a produzir uma interpretação mais detalhada sobre o MMM no Brasil. É nesta perspectiva que o GHEMAT vem desenvolvendo seus projetos de investigação, com o intuito de produzir história a partir do trabalho com documentos em vez de monumentos.

\section{Referências}

BÜRIGO, Elisabete Zardo. Movimento da matemática moderna no Brasil: estudo da ação e do pensamento de educadores matemáticos nos anos 60. Dissertação (Mestrado em Educação) - Faculdade de Educação, Universidade Federal do Rio Grande do Sul. Porto Alegre, 1989.

D’AMBRÓSIO, Beatriz Silva. The Dynamics and consequences of the modern mathematics reform movement for Brazilian mathematics education. Thesis (Doctor of Philosophy) - Indiana University, 1987.

KLINE, Morris. 0 fracasso da Matemática Moderna. São Paulo,SP: Ibrasa, 1976.

LEGOFF, Jacques Documento/monumento. In: . História e Memória. Campinas: Editora da UNICAMP, 1992. p. 535-549.

SOARES, Flávia dos Santos. Movimento da Matemática Moderna no Brasil: Avanço ou Retrocesso? Dissertação (Mestrado em Matemática) - Pontifícia Universidade Católica do Rio de Janeiro, 2001.

STEPHAN, Ana Maria. Reflexão histórica sobre o movimento da matemática moderna em Juiz de Fora. Dissertação de mestrado - Universidade Federal de Juiz de Fora, 2000.

VALENTE, Wagner Rodrigues. História da educação matemática: interrogações metodológicas. [S. l.:S. n.], 2005. (prelo).

VITTI, Catanina Maria. Movimento da matemática moderna: memónia, vaias e aplausos. Tese (Doutorado em Educação) - Universidade Metodistade Piracicaba, 1998.

Recebido: 08 de fevereiro de 2006.

Aprovado: 28 de março de 2006. 